Copyright (C) 2015 by Academic Publishing House Researcher

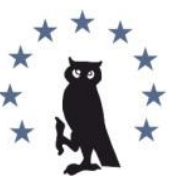

Published in the Russian Federation

European Researcher

Has been issued since 2010.

ISSN 2219-8229

E-ISSN 2224-0136

Vol. 100, Is. 11, pp. 719-728, 2015

DOI: 10.13187/er.2015.100.719

www.erjournal.ru

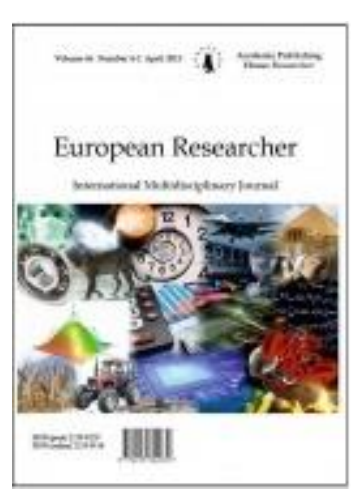

UDC $339.97+338.43$

\title{
The Development of Petroleum Refining in the World Market Dimensions of Sustainable Development
}

\author{
Alexey S. Shapran \\ Taras Shevchenko National University of Kyiv, Institute of International Relations, Ukraine \\ Postgraduate student \\ E-mail: ashapran@yandex.ru
}

\begin{abstract}
The development of petroleum refining in the world market dimensions of sustainable development investigated by the author's interpretation of the OECD model "pressure - state response", where the pressure parameters proposed use - $\mathrm{CO} 2$ emissions, the state parameters indicators of output and foreign trade refining sector; indicators to community response - (GDP eco-intensity). On the basis of economic and mathematical modeling performed of the adaptation and their value for use in the model parameters, performed a quantitative assessment of the relationship between the key requirements for sustainable development and development of the world petroleum refining market. This approach gave to perform a quantitative assessment of the level and impact of individual factors on the development of world petroleum market in countries with different technological structures.

Keywords: world market, petroleum products, sustainable development, energy intensity of GDP, eco-intensity, carbon intensity.

\section{Введение}

Достижения приоритетов устойчивого развития предполагает учет экономических, социальных и экологических параметров эффективности, достижение которых возможно при условии взаимодействия государственного регулирования и внедрения практики ответственного бизнеса. Существует много методик оценки взаимовлияния хозяйственной деятельности и окружающей среды. Оценка уровня устойчивого развития на мировом рынке нефтепродуктов предусматривает разработку соответствующих критериев и показателей с учетом экономических, социальных и экологических параметров эффективности. По схеме модели ОЭСР «Давление - стостояние - реакция» на англ. "Pressure - State - Response» (PSR) классификация индикаторов устойчивого развития проводится по трем типам: давления, состояния и реакции. Показатели давления применяют для описания влияния человеческой деятельности на окружающую среду; показатели состояния - для отражения отношение к качеству окружающей среды и качества и количества природных ресурсов (разрабатываются, чтобы предоставить общее представление о состоянии окружающей природной среды и его развитие во времени); показатели реакции общества - для отображения действий: как общество реагирует на изменение окружающей среды (смягчение, адаптация или предупреждения негативного воздействия человека на
\end{abstract}


окружающую среду, прекращение или изменение ущерба, уже был нанесен окружающей среде, сохранение и охрана природы и природных ресурсов). Отсутствует единая методика оценки устойчивого развития мирового отраслевого рынка.

Развитие мирового рынка продуктов нефтепереработки учитывая его значение для энергетического и неэнергетического сектора мирового хозяйства, воздействия на окружающую природную среду на всех стадиях, значительный социальный эффект и зависимость от внедрения новых технологий, прямо и косвенно касается всех жителей планеты Земля. Поэтому совершенствование мотодики оценки уровня устойчивого развития на мировом рынке нефтепродуктов по отдельным показателям является важным и актуальным научным заданием.

\section{Цели исследования}

Изучить развитие мирового рынка нефтепродуктов в измерениях устойчивого развития, осуществить количественную оценку взаимосвязи между ключевыми требованиями устойчивого развития и развития мирового рынка нефтепереработки.

\section{Материалы и методы}

Теоретические разработки по оценке устойчивого развития предложено во многих научных работах, в частности Б. Молдан, С. Билгарц, Р. Матераверз исследовали применение показателей устойчивого развития [1]. Х. Боссель систематизировал теории, методы, применение показателей устойчивого развития [2]. Н. Булетова рассматривала сущность, содержание и проблемы диагностики эколого-экономической безопасности в регионах России [3]. Ю. Маковецкая предложила интегрированные показатели обращения с отходами как инструментарий для измерения и репрезентации эколого-экономических тенденций в Украине в собственной интерпретации модели PSR OЭCP [4]. Л. Бугаева, M. Османов, Г. Статюха предлагают применение метода системной динамики [5]. М. Пашкевич, А. Чернышева, Т. Гвиниашвили разработали системно-динамическую имитационную модель устойчивого развития территориальных производственных систем [6]. И. Смачило проанализировали методы управления устойчивым развитием предприятия [7]. Н. Тарасова, Е. Кручина исследовали подходы авторитетных международных организаций к формированию индексов и индикаторов устойчивого развития [8].

Энергоемкость ВВП стран определяется как отношение валового объема потребления топливно-энергетических ресурсов производственной и невиробночою сферами к ВВП страны за определенный период, измеряется в ТДж / тысячу долларов США. Одним из показателей, которым характеризует эффективность использования энергии является энергоемкость ВВП. Исследования многих ученых свидетельствуют в целом намного ниже показатели энергоемкости развитых стран по сравнению со странами, с формирующимися рынками. В странах с формирующимися рынками значительно более высокие показатели энергоемкости ВВП сопровождаются более высокой эмиссией $\mathrm{CO}_{2}$ по сравнению с развитыми странами.

Экологическая составляющая развития характеризуется многими показателями, однако особое место среди них принадлежит показателю «интенсивность экологических выбросов», или эко-интенсивность, этот термин в большинстве исследований рассматривается как углеродоемкость или интенсивность выбросов $\mathrm{CO}_{2}$ в ВВП то есть является суммарным объемом всех выбросов $\mathrm{CO}_{2}$-эквивалента в расчете на 1 тысячу долларов США в ВВП страны.

Таким образом, углеродоемкость применяется для оценки удельного влияния хозяйственной деятельности на окружающую среду, в т.ч. относительно топливопотребления. Теоретические разработки по использованию данного показателя предложено во многих научных трудах. В частности А. Н. Горский применяет их для исследования неравенства устойчивого развития регионов Украины в дискурсе экологической безопасности [9], А.В. дер Воет и Н. Ейзенменжер рассматривают эко-интенсивность в системе показателей эффективности использования ресурсов и в контексте тесных связей с экологической эффективностью [10]. П. Петерсон и А. Грандос применяют показатель эко-интенсивности в наборе с инновационными показателей для формирования парадигмы мероприятий управления и превентивных стратегий местной и 
национальной власти согласно производственным циклом [11]. А. Дячук, Г. Подолець, Б. Серебренников, Т. Зеленюк проанализировали эффективность использования энергетических ресурсов в мировой экономике и с использованием модели «TIMESУкраина» рассчитали энергетические экологические показатели (индикаторы) долгосрочного развития государства в условиях отсутствия значительных реформ в энергетическом секторе, сформулировали рекомендации для интенсификации трансформации современной энерго-экологической политики в политику устойчивого развития энергетики Украины [12]. Г. Елисеева предлагает применение в системе статистической оценки динамики зеленой экономики [13]. Поэтому нами в качестве индикатора давления в анализе влияния требований устойчивого развития на трансформацию мировой нефтеперерабатывающей сферы предложено использовать показатель эмиссии $\mathrm{CO}_{2}$.

Анализ функционирования мирового рынка представлен в трудах В. Бурлаки [14], А. Кратта, И. Кирноса [15], С. Февраля, Б. Кочирко, Л. Щербининой [16], Дж. Мюельбауера, Л.Нунциата [17]. Вместе с тем, не получили должного исследования вопросы оценки устойчивого развития на мировом рынке нефтепродуктов.

\section{Методология}

Нами предложена интерпретация модели ОЭСР «Давление - состояние - реакция» для последующей оценки влияния требований устойчивого развития на трансформацию мирового рынка нефтепереработки (представлено на рис. 1).

\section{Інформація}

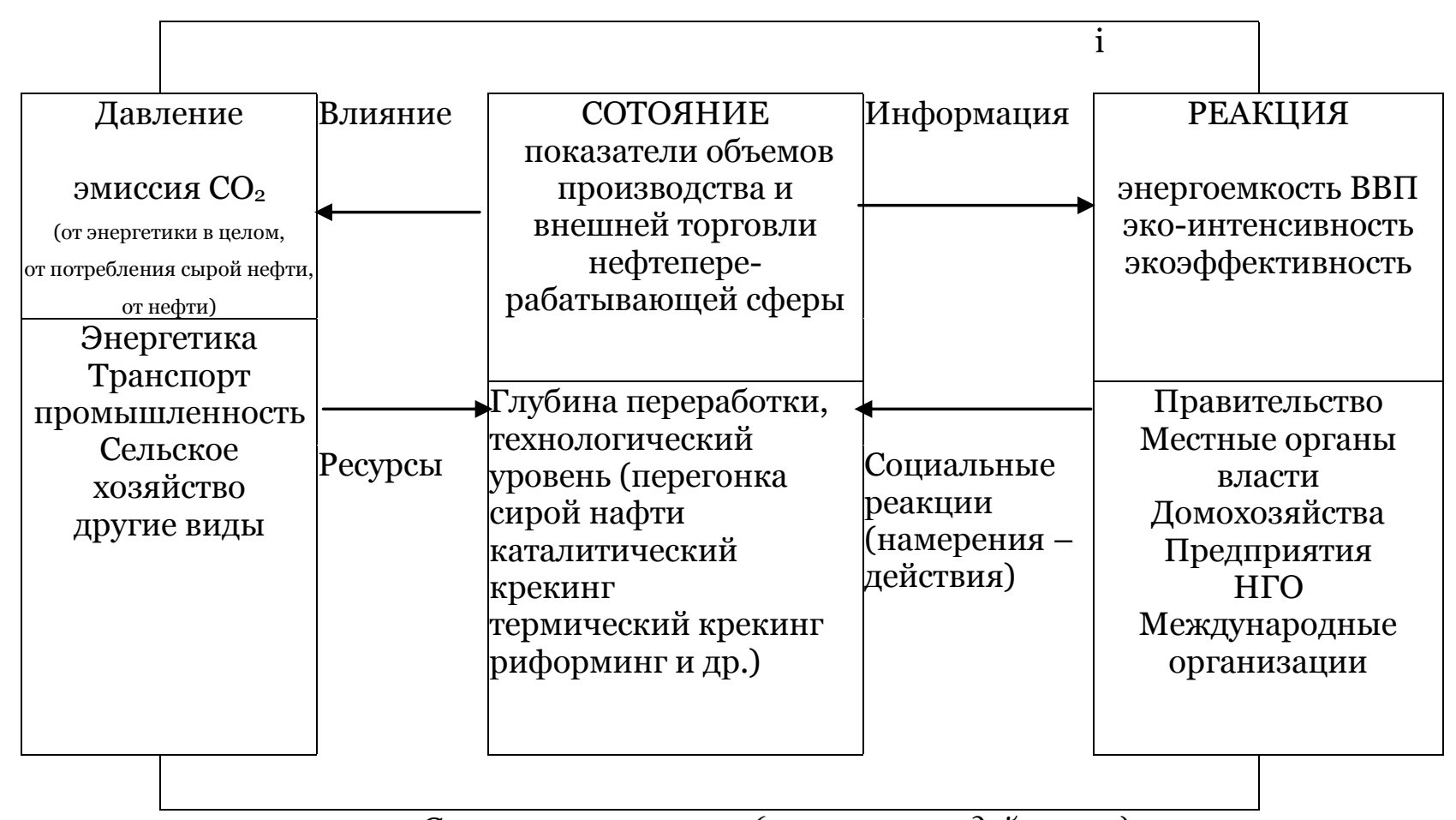

Источник: составлено автором

Социальные реакции (намерения - действия)

Puc. 1. Интерпретация модели ОЭСР «Давление - состояние - реакция» для оценки развития мирового рынка нефтепереработки в измерениях устойчивого развития

Авторская интерпретация модели ОЭСР для изучения влияния развития мирового рынка нефтепереработки позволяет построить авторскую эконометрическую модель выявления характера связи между факторами и осуществления количественной оценки параметров «Состояние» и «Реакция» на «Давление» (зависимая переменная). 
Эмпирическая база исследования представляет собой комплекс методов обработки статистической информации, которая охватывает данные по 202 странам и территориям мира за 2011 г. Поскольку это последний год, за который имеются возможность сопоставить параметры представленных в табл.1.

Таблица 1

\section{Параметры модели «Давление - состояние - реакция» в оценке влияния требований устойчивого развития на трансформацию мирового рынка нефтепереработки}

\begin{tabular}{|l|l|l|}
\hline Показатели «Давления» & $\begin{array}{l}\text { Показатели «Состояния» } \\
\text { (тыс баррелей / день) }\end{array}$ & Показатели «Реакции» \\
\hline Эмиссия $\mathrm{CO}_{2}$ метрических & перегонка сырой нефти & эко-интенсивность (эмиссия \\
тонн) & метрических тонн двуокиси \\
эмиссия $\mathrm{CO}_{2}$ от потребления & экспорт сырой нефти & углерода в ВВП) \\
нефти (метрических тонн) & импорт сырой нефти & энергоемкость ВВП (ТДж / \\
эмиссия $\mathrm{CO}_{2}$ от потребления & каталитический крекинг & тысяч долларов США) \\
энергии (метрических тонн) & термический крекинг & \\
численность населения (млн & риформинг \\
человек) & импорт нефтепродуктов & \\
ВВП (тысяч долларов США) & экспорт нефтепродуктов & \\
& производство \\
& автомобильного бензина & \\
& производство реактивного & \\
& топлива & \\
& производство керосина & \\
& производство дистиллята & \\
& производство мазута & \\
& производство пропан-бутана & \\
& (тысяч м куб. / день) & \\
& производство других & \\
& нефтепродуктов & \\
& общее производство & \\
& нефтепродуктов &
\end{tabular}

Источник: составлено автором по данным [18-20].

Основными критериями отбора показателей была их соответствие следующим требованиям:

- воздействию;

- легко и однозначно интерпретироваться;

- сочетать экологические, социальные и экономические аспекты;

- быть научно обоснованными;

- иметь количественное выражение;

- быть репрезентативными.

Устойчивое развитие на мировом рынке нефтепереработки означает сбалансированный рост при снижении энергоемкости, повышения производительности труда, повышение экологичности производства, повышения качества продуктов первичной и вторичной переработки, расширение предложения ассортимента нефтепродуктов, совершенствование условий и оплаты труда сотрудников.

\section{Результаты исследования}

Для многофакторных моделей или явлений целесообразно использовать методы множественного корреляционно-регрессионного анализа, которые позволяют изучить и количественно оценить внутренние и внешние следственные связи между образующими 
модель факторами и установить закономерности функционирования и тенденции развития исследуемой результативного признака.

Основная задача корреляционного и регрессионного методов анализа заключается в анализе статистических данных для выявления математической зависимости между исследуемыми признаками и установки с помощью коэффициентов корреляции сравнительной оценки плотности взаимосвязи, который имеет определенный числовое выражение.

Комплексное взаимодействие всех факторов $\left(\mathrm{x}_{1}, \mathrm{x}_{2}, \ldots . . \mathrm{x}_{\mathrm{n}}\right)$ c результативным показателем (Y) можно описать уравнением линейной многофакторной регрессии, которое описывает зависимость между результативной переменной Y (параметры «давления») и некоторыми влиятельными параметрами «состояния» и «реакции» По результатам корреляционного анализа параметров модели «Давление - состояние - реакция» в оценке влияния требований устойчивого развития мирового рынка нефтепереработки определим факторы, которые имеют высокий уровень связи. Наибольшее влияние на выбросы производят факторы технологии производства нефтепродуктов, производственная перегонка сырой нефти (очень высокая корреляция - 0,981), термический крекинг (высокая корреляция - 0,88), риформинг нефти (очень высокая корреляция - 0,941), рост экспорта нефти (очень высокая корреляция - 0,959), способствует наращиванию производственных мощностей, импорт нефтепродуктов нефти (очень высокая корреляция - 0,969) и население (очень высокая корреляция - 0,974), связанные со спросом на нефтепродукты со стороны транспорта. Построим линейную эконометрическую модель и запишем общий вид такой модели (1):

$$
Y_{\mathrm{CO}_{2}}=a_{0}+a_{1} x_{1}+a_{2} x_{2}+a_{3} x_{3}+a_{4} x_{4}+a_{5} x_{5}+a_{6} x_{6}+a_{7} x_{7}
$$

В этой модели $a_{i}(i=0,1, \ldots, 7)$ - оценки параметров модели (1), которые необходимо количественно измерить на основе заданной эмпирической информации.

Каждое наблюдение дает ежегодную количественную оценку выбросов углерода и каждого из факторов, влияющих на эту величину. Фактические и рассчитанные показатели близки и имеют незначительные различия. При этом оказалось, что статистические характеристики удовлетворяют исходную гипотезу только по показателям: термический крекинг, риформинг, энергоемкость ВВП.

В результате расчетов в программном пакете SPSS получено многофакторное уравнение регрессии со свободным членом (2):

$$
\mathrm{Y}_{\mathrm{CO}_{2}}=-57,160+0,892 \cdot \mathrm{x}_{1}+0,354 \cdot \mathrm{x}_{2}-2,87 \cdot \mathrm{x}_{3}+0,001 \cdot \mathrm{x}_{4}+0,225 \cdot \mathrm{x}_{5}-0,681 \cdot \mathrm{x}_{6}+0,668 \cdot \mathrm{x}_{7}(2) \text {, }
$$

где зависимая переменная $\mathrm{Y}_{\mathrm{CO}_{2}}$ это эмиссия $\mathrm{CO}_{2}$ эквивалента; $\mathrm{x}_{1}$ - перегонка сирой нефти; $\mathrm{x}_{2}-$ термический крекинг; $\mathrm{x}_{3}-$ риформинг; $\mathrm{x}_{4}-$ еэнергоєемкость; $\mathrm{x}_{5}-$ импорт нефтопродуктов; $\mathrm{x}_{6}$ - экспорт нефтопродуктов; $\mathrm{x}_{7}-$ численность населения.

Таблица 5

\begin{tabular}{|c|c|c|c|c|}
\hline \multirow[b]{2}{*}{ Model } & \multicolumn{2}{|c|}{$\begin{array}{l}\text { Unstandardized } \\
\text { Coefficients }\end{array}$} & \multirow{2}{*}{$\begin{array}{c}\text { Standardized Coefficients } \\
\text { Beta }\end{array}$} & \multirow[b]{2}{*}{ Sig. } \\
\hline & $\mathrm{B}$ & Std. Error & & \\
\hline (Constant) & 57,160 & 26,629 & & o,033 \\
\hline x & 0,892 & 0,085 & 1,933 & 0,000 \\
\hline Х & 0,354 & 0,318 & 0,090 & 0,267 \\
\hline $\mathrm{x}_{3}-$ риформинг & $\begin{array}{r}- \\
2,870\end{array}$ & 0,481 & $-1,069$ & 0,000 \\
\hline
\end{tabular}

\section{Coefficients $^{\mathbf{a}}$}




\begin{tabular}{|l|r|r|r|r|}
$\mathrm{x}_{4}-$-энергоемкость ВВП & 0,001 & 0,001 & 0,016 & 0,497 \\
$\mathrm{x}_{5}$-импорт нефтопродуктов & 0,225 & 0,092 & 0,081 & 0,015 \\
$\mathrm{x}_{6}-$-экпорт нефтопродуктов & - & 0,090 & $-0,370$ & 0,000 \\
& 0,681 & & & \\
$\mathrm{x}_{7}-$ численность населения & 0,668 & 0,325 & 0,119 & 0,041 \\
\hline
\end{tabular}

a. Dependent Variable: Емісія $\mathrm{CO}_{2}$

Рассчитанный коэффициент множественной корреляции $\mathrm{R}=0,946$ указывает на существование достаточно плотного связи что между факторными и результативным признаками. Коэффициент детерминации, $\mathrm{R}^{2}$, - оценка качества уравнения регрессии. Совокупный коэффициент множественной детерминации $\mathrm{R}^{2}=0,895$ свидетельствует о том, что вариация эмиссия $\mathrm{CO}_{2}$ на 89,5 \% обусловлена факторами, введенными в регрессионную модель. Это означает, что выбранные факторы существенно влияют на исследуемый показатель. Как свидетельствуют статистические характеристики, полученная модель высокого качества. Проверку модели на адекватность здйснено по тесту Дарбина-Уотсона, поскольку в нашем случае показатель приближается к 2, то модель адекватна. Однако значение Sig. (значимость) для термического крекингу и энергоемкости выше 0,05, то есть эти параметры можно не учитывать.

Model Summaryb

Таблица 4

\begin{tabular}{|l|c|r|r|r|r|}
\hline Model & $\mathrm{R}$ & R Square & $\begin{array}{c}\text { Adjusted R } \\
\text { Square }\end{array}$ & $\begin{array}{c}\text { Std. Error of the } \\
\text { Estimate }\end{array}$ & Durbin-Watson \\
\hline 1 & $0,946^{\mathrm{a}}$ & 0,895 & 0,892 & 243,896 & 1,88 \\
\hline
\end{tabular}

Величина постоянного члена указывает на значительное значение зависимой переменной с нулевого значения независимых переменных, то есть при отсутствии деятельности нефтеперерабатывающих предприятий, использование нефтепродуктов и внешней торговли нефтепродуктами эмиссия $\mathrm{CO} 2$ будет иметь отрицательное значение 57,16 . Это означает, что включены независимые переменные в полученное уравнение не в полной мере описывает влияние факторов на эмиссию $\mathrm{CO} 2$, понятно, поскольку существуют и другие секторы экономики, которые также влияют на зависимую переменную.

Размер стандартных ошибок свидетельствует, что в условиях доверительного интервала 95 \% каждый коэффициент может отклоняться от среднего значения на $\pm 2 \cdot \mathrm{Std}$. Error. Таким образом величина эмиссии СО2 при отсутствии влияния включенных в модель факторов может отклоняться от среднего значения $-57,16$ на $\pm 2 \cdot 26,629$, равной 53,258 т.

Стандартизированные коэффициенты регрессии (Beta) показывают относительную значимость независимых переменных, включенных в регресийгу модель, то есть указывают на то как сильно влияют исследуемые факторы на зависимую переменную. Как видно из табл. 5 наибольшую значимость имеет первая независимая переменная $\mathrm{x}_{1}-$ перегонка сырой нефти (Beta $=1,933)$, то есть объем перегонки сырой нефти может в 1,8 раза увеличивать эмиссию $\mathrm{CO}_{2}$ по сравнению с последующим по значению показателем $\mathrm{x}_{3}$ риформинг (Beta = -1,069), в пять раз больше показателя экспорта нефтепродуктов (Beta $=-0,37$ ) и в разы больше других показателей. Объяснение этому заключается в первичности объемов перегоники сырой нефти по сравнению с технологиями более глубокой ее переработки.

В столбце Sig. Табл. 5 Coefficients представлен уровень значимости для каждого регрессионного коэффициента. При $5 \%$-ном уровне значимости можно считать неравными нулю только те коэффициенты, для которых значение Sig. не превышают 0,05. Как видно из табл. 5 к таким коэффициентам относится значение Sig. для термического крекинга $(0,267)$ и энергоемкости $(0,497)$, которые выше 0,05, то есть эти параметры можно не учитывать. 
Значение показателя «статистическая значимость» в расчете ANOVA равно о,оо, что меньше 0,5, то есть регрессионная модель, полученная на основе данных по выбранным показателям рынка справедлива для всей генеральной совокупности в целом.

Таким образом, интерпретация полученной багатофактонои регрессионной модели заключается в выявлении наиболее значимого показателя, которым является глубокая переработка нефти - риформинг. При росте использования риформинга на НПЗ стран мира на 1 тысячу баррелей в день объем выбросов $\mathrm{CO}_{2}$ снижается на $-2,87$ тонн, что свидетельствует о влиянии требований устойчивого развития на мировой рынок нефти.

\section{Заключение}

Авторская интерпретация модели ОЭСР «Давление - состояние - реакция» о влиянии требований устойчивого развития на трансформацию мирового рынка позволила построить эконометрическую модель для выявления характера связи между факторами и осуществления количественной оценки параметров развития свитовго рынке нефтепереработки. Такой подход позволяет использовать общедоступные данные для межстрановых сравнительного анализа с учетом экономических, социальных и экологических параметров. Таким образом интерпретация полученной багатофактонои регрессионной модели заключается в выявлении наиболее значимого показателя, которым является глубокая переработка нефти - риформинг. При росте использования реформинга на НПЗ стран мира на 1 тыс. Баррелей в день объем выбросов $\mathrm{CO} 2$ снижается на -2,87 т, что свидетельствует, что чем выше глубина переработки нефти, тем меньше негативное воздействие на окружающую среду.

Дальнейшие исследования оценки уровня устойчивого развития на мировом рынке нефтепродуктов предусматривают усовершенствование применения методик расчета интегральных индексов

\section{Примечания:}

1. Moldan B. Sustainability Indicators: A Report on the Project on Indicators of Sustainable Development / B. Moldan , S. Billharz, R. Materavers. New York, Toronto: JOHN WELEY \& SONS, 1997. $415 \mathrm{p}$.

2. Bossel H. (1999) Indictors for sustainable development: Theory, method, applications / Hartmut Bossel. Published by the International Institute for Sustainable Development. Winnipeg, Manitoba Canada.

3. Булетова Н.Е. Эколого-экономическая безопасность: природа, содержание и проблемы диагностики в регионах России: монография / Н.Е. Булетова. Волгоград: Волгоградский филиал РГТЭУ, 2013. 220 с.

4. Маковецька Ю.М. Інтегровані показники поводження 3 відходами як інструментарій для виміру та репрезентації еколого-економічних тенденцій в Україні // Економіка природокористування і охорони довкілля. 2009. С. 183-189.

5. Бугаєва Л.М. Використання методів системної динаміки для дослідження сталого розвитку регіонів україни / Л.М. Бугаєва, М.М. Османов, Г.О. Статюха // ВосточноЕвропейский журнал передовых технологий. № 2/10 ( 44 ) 2010. С. 22-25.

6. Пашкевич М.С. Моделювання сталого розвитку територіальних виробничих систем / М. С. Пашкевич, О.С. Чернишева, Т.З. Гвініашвілі // Регіональна економіка. №1. 2013. C. $173-178$.

7. Смачило I.I. Методи управління сталим розвитком підприємства / I.I. Смачило // Економіка підприємства та управління виробництвом. 2012. С. 115-120.

8. Тарасова Н.П. Индексы и индикаторы устойчивого развития / Н. П. Тарасова, Е. Б. Кручина // Устойчивое развитие: Природа-Общество-Человек. Т.2. (2002). С. 127-144.

9. Горський А.М. Дослідження нерівності сталого розвитку регіонів України в дискурсі екологічної безпеки // Ефективна економіка. http://www.economy.nayka.com. $\mathrm{ua} /$ ?op $=1 \& \mathrm{z}=2511$

10. Ester van der Voet, Nina Eisenmenger Topical paper 9: Indicators for resource efficiency - potential way of representing results // Study name Assessment of Scenarios and Options 
towards a Resource Efficient Europe http://ec.europa.eu/environment/ enveco/resource_efficiency/pdf/TP9.pdf

11. Peterson P.J., Granados A. Towards sets of hazardous waste indicators. Essential tools for modern industrial management. // Environ Sci Pollut Res Int. 2002 ;9(3):204-14. Peterson P.J., Granados A.

12. Дячук О.А. Ефективність і екологічність використання енергетичних ресурсів у світі та Україні [Текст] / О.А. Дячук, Р.З. Подолець, Б.С. Серебренніков, Т.А. Зеленюк // Економічний аналіз : зб. наук. праць / Тернопільський національний економічний університет; редкол.: В.А. Дерій (голов. ред.) та ін. - Тернопіль : Видавничо-поліграфічний центр Тернопільського національного економічного університету «Економічна думка», 2014. Toм 15. № 1. C. 59-75.

13. Єлісєєва Г.Ю. Статистичне оцінювання розвитку зеленої економіки в Україні / Г.Ю. Єлісєєва // Віснику Дніпропетровського національного університету. Серія: Економіка. http://vestnikdnu.com.ua/archive/201372/elliseeva.html

14. Бурлака В. Г. Сучасні тренди науково-технологічного розвитку та їх роль у нафтовому секторі / В.Г. Бурлака // Актуальні проблеми економіки . 2013. № 5. С.54-65. [Електронний ресурс]. Режим доступу: http://nbuv.gov.ua/j-pdf/ape_2013_5_8.pdf

15. Кратт О.А. Світовий ринок нафти вибір інструментарію пізнання / О. А. Кратт, I. О. Кірнос // Научные труды ДонНТУ. - Серия: экономическая. - Выпуск 37-2. [Електронний pecypc]. Режим доступу: http://vuzlib.com.ua/articles/book/13515-Sv\%D1\%96tovijj_ rinok_ nafti_vib\%D1\%96r_/1.html

16. Лютий С.М. Сучасний стан і тенденції розвитку нафтопереробної промисловості світу / С. М. Лютий, Б. Ф. Кочірко, Л. О. Щербініна // Вісник НАУ. 2009. №1. С. 134-138.

17. Muelbauer J. Credit, the stock market and oil / Muelbauer J. and L. Nunziata, University of Oxford,Working paper, (2001), June.

18. Report for Selected Countries and Subjects. World Economic and Financial Surveys World Economic Outlook Database. [Electronic resource]. Access: http://www.imf.org/external/pubs/ft/weo/2015/o2/weodata/index.aspx

19. Сайт Адміністрації енергетичної інформації Міністерства енергетики США [Електронний ресурс]. Режим доступу: www.eia.gov

20. Final database of environmental satellite accounts: technical report on their compilation Aurélien Genty, Iñaki Arto, and Frederik Neuwahl (IPTS) WIOD Deliverable 4.6, Documentation April 2012.

\section{References:}

1. Moldan B. Sustainability Indicators: A Report on the Project on Indicators of Sustainable Development / B. Moldan, S. Billharz, R. Materavers. New York, Toronto: JOHN WELEY \& SONS, 1997. $415 \mathrm{p}$.

2. Bossel H. (1999) Indictors for sustainable development: Theory, method, applications / Hartmut Bossel. Published by the International Institute for Sustainable Development. Winnipeg, Manitoba Canada.

3. Buletova N.E. Ekologo-ekonomicheskaya bezopasnost': priroda, soderzhanie i problemy diagnostiki v regionakh Rossii: monografiya / N.E. Buletova. Volgograd: Volgogradskii filial RGTEU, 2013. 220 s.

4. Makovets'ka Yu.M. Integrovani pokazniki povodzhennya $\mathrm{z}$ vidkhodami yak instrumentarii dlya vimiru ta reprezentatsiï ekologo-ekonomichnikh tendentsii v Ukraïni // Ekonomika prirodokoristuvannya i okhoroni dovkillya. 2009. S. 183-189.

5. Bugaєva L.M. Vikoristannya metodiv sistemnoï dinamiki dlya doslidzhennya stalogo rozvitku regioniv ukraïni / L.M. Buga€va, M.M. Osmanov, G.O. Statyukha // VostochnoEvropeiskii zhurnal peredovykh tekhnologii. № 2/10 ( 44 ) 2010. S. $22 \square 25$.

6. Pashkevich M.S. Modelyuvannya stalogo rozvitku teritorial'nikh virobnichikh sistem / M. S. Pashkevich, O.S. Chernisheva, T.Z. Gviniashvili // Regional'na ekonomika. №1. 2013. S. 173178.

7. Smachilo I.I. Metodi upravlinnya stalim rozvitkom pidpriemstva / I.I. Smachilo // Ekonomika pidpriemstva ta upravlinnya virobnitstvom. 2012. S. 115-120. 
8. Tarasova N.P. Indeksy i indikatory ustoichivogo razvitiya / N. P. Tarasova, E.B. Kruchina // Ustoichivoe razvitie: Priroda-Obshchestvo-Chelovek. T.2. (2002). S. 127-144.

9. Gors'kii A.M. Doslidzhennya nerivnosti stalogo rozvitku regioniv Ukraïni v diskursi ekologichnoï bezpeki // Efektivna ekonomika. http://www.economy.nayka.com. ua/?op=1\&z=2511

10. Ester van der Voet, Nina Eisenmenger Topical paper 9: Indicators for resource efficiency - potential way of representing results // Study name Assessment of Scenarios and Options towards a Resource Efficient Europe http://ec.europa.eu/environment/ enveco/resource_efficiency/pdf/TP9.pdf

11. Peterson P.J., Granados A. Towards sets of hazardous waste indicators. Essential tools for modern industrial management. // Environ Sci Pollut Res Int. 2002 ;9(3):204-14. Peterson P.J., Granados A.

12. Dyachuk O.A. Efektivnist' i ekologichnist' vikoristannya energetichnikh resursiv u sviti ta Ukraïni [Tekst] / O.A. Dyachuk, R.Z. Podolets', B.S. Serebrennikov, T.A. Zelenyuk // Ekonomichnii analiz : zb. nauk. prats' / Ternopil's'kii natsional'nii ekonomichnii universitet; redkol.: V. A. Derii (golov. red.) ta in. - Ternopil' : Vidavnicho-poligrafichnii tsentr Ternopil's'kogo natsional'nogo ekonomichnogo universitetu «Ekonomichna dumka», 2014. Tom 15. № 1. S. 59-75.

13. Elise€va G.Yu. Statistichne otsinyuvannya rozvitku zelenoï ekonomiki v Ukraïni / G. Yu. Elise€va // Visniku Dnipropetrovs'kogo natsional'nogo universitetu. Seriya: Ekonomika. http://vestnikdnu.com.ua/archive/201372/elliseeva.html

14. Burlaka V.G. Suchasni trendi naukovo-tekhnologichnogo rozvitku ta ïkh rol' u naftovomu sektori / V.G. Burlaka // Aktual'ni problemi ekonomiki . 2013. № 5. S. 54-65. [Elektronnii resurs]. Rezhim dostupu: http://nbuv.gov.ua/j-pdf/ape_2013_5_8.pdf

15. Kratt O.A. Svitovii rinok nafti vibir instrumentariyu piznannya / O. A. Kratt, I. O. Kirnos // Nauchnye trudy DonNTU. - Seriya: ekonomicheskaya. Vypusk 37-2. [Elektronnii resurs]. Rezhim dostupu: http://vuzlib.com.ua/articles/book/13515-Sv\%D1\%96tovijj_rinok_nafti _vib\%D1\%96r_/1.html

16. Lyutii S.M. Suchasnii stan i tendentsiï rozvitku naftopererobnoï promislovosti svitu / S.M. Lyutii, B.F. Kochirko, L. O. Shcherbinina // Visnik NAU. 2009. №1. S. 134-138.

17. Muelbauer J. Credit, the stock market and oil / Muelbauer J. and L. Nunziata, University of Oxford,Working paper, (2001), June.

18. Report for Selected Countries and Subjects. World Economic and Financial Surveys World Economic Outlook Database. [Electronic resource]. Access: http://www.imf.org/external /pubs/ft/weo/2015/o2/weodata/index.aspx

19. Sait Administratsiï energetichnoï informatsiï Ministerstva energetiki SShA [Elektronnii resurs]. Rezhim dostupu: www.eia.gov

20. Final database of environmental satellite accounts: technical report on their compilation Aurélien Genty, Iñaki Arto, and Frederik Neuwahl (IPTS) WIOD Deliverable 4.6, Documentation April 2012.

УДК 33

\title{
Развитие мирового рынка в измерениях устойчивого развития
}

\author{
Алексей Сергеевич Шапран
}

Киевский национальный университет имени Тараса Шевченко, Украина Аспирант

Аннотация. Развитие мирового рынка нефтепродуктов в измерениях устойчивого развития исследовано с помощью авторской интерпретации модели ОЭСР «давление состояние - реакция», где в качестве параметров «давления» предложено использовать эмиссию $\mathrm{CO}_{2}$ эквивалента; параметров состояния - показатели объемов производства и внешней торговли нефтеперерабатывающей сферы; показателей «реакции» общества (энергоекость ВВП, эко-интенсивность и др.). На основе экономико-математического моделирования сделана количественная оценка взаимосвязи между ключевыми 
требованиями устойчивого развития и развития мирового рынка нефтепереработки путем адаптации, систематизации и отбора по их значению для использования в модельних расчетах параметров модели. Этот подход дал возможность количественно измерить и оценить уровень влияния отдельных факторов на развитие мирового рынка нефтепереработки в странах с различными технологическими укладами.

Ключевые слова: мировой рынок, нефтепродукты, устойчивое развитие, энергоемкость ВВП, эко-интенсивность, углеродо-интенсивнисть. 